\title{
Firms' Perspective on Technology Relatedness and Adaptation: A Survey on Renewable Energy Firms
}

\author{
Abdullah Kaya, Toufic Mezher, and I-Tsung Tsai
}

\begin{abstract}
This paper investigates firms' perspective on technology relatedness and adaptation with an intent to understand the dynamics of technology diffusion across industries. The result from a survey on renewable energy firms shows that the surveyed firms are actively monitoring and evaluating the possibility of adapting their existing technologies for new applications. However, they are more interested in improving competitiveness in core applications than exploring opportunities in new applications. This preference is reflected in their higher priority for developing complementary technologies for existing applications than adapting existing technology for new applications. The result implies that core business competency tends to have greater influence than technology relatedness on firms' technology development strategies. Further investigation is needed to identify industry characteristics on firm's perspective on technology adaptation strategy.
\end{abstract}

Index Terms-Technology strategy, technology relatedness, complementary technology, technology adaptation.

\section{INTRODUCTION}

This paper analyzes firms' perspective on technology relatedness and technology adaption with a survey on renewable energy firms. Technology relatedness refers to the situation where two or more technologies share certain common scientific principles [1]. A technology can be adapted to be used for a new application if the technology for the new application and the original technology are related technologies [2]. For example, both thin film transistor-liquid crystal display (TFT-LCD) and flat panel display (FPD) deposition techniques can be applied in production of thin film solar cells [3], [4]. As a result, the deposition methods for the production of TFT-LCD and FPD are related technology to solar cells production technology. When two technologies are related, their corresponding applications are related applications. Following the previous example, the applications of flat panel display and solar energy production are related applications. As argued by Breschi et al. [1], firms constantly seek opportunities in new applications where they may leverage their existing technologies to deliver a new solution. Empirical research on technology development did show that firms adapt their knowledge and experience into different but related applications [1]-[5]. While technology

Manuscript received May 4, 2014; revised July 21, 2014. This work was supported by funding from the Abu Dhabi Government and the Masdar Corporate. We appreciate helpful comments from Nawal Al Hosany, Zhanna Kapsalyamova, and Sanna El Waddi.

The authors are with the Department of Engineering Systems and Management, Masdar Institute of Science and Technology, Abu Dhabi, United Arab Emirates (e-mail: akaya@masdar.ac.ae,tmezher@masdar.ac.ae, itsai@masdar.ac.ae). adaptation exists, it is not clear how important technology adaptation affects technology development strategies. The answer to this question provides important implication on the dynamics of technology diffusion across industries. This paper serves to fill this intellectual gap.

We conducted a survey on renewable energy firms to identify their perspectives on technology relatedness and adaptation. The result shows that the majority of the surveyed firms are actively developing in-house patents for the technologies of their core application of focus. More than half of the firms are aware of the opportunity of adapting their technology to different applications and have identified related applications to their technology. Among the surveyed firms that have defined related applications, majority of them indicate that applicability of their technologies are more important than expected short term profit in the decision-making of their technology strategy. On the other hand, firms are more interested in developing technology for core and complementary applications. This may infer that firms are in general more concerned about increasing competitiveness in core applications than generating short term profit from expanding in new applications. We also find that the surveyed firms are not very interested in replacing their technology with another technology adaptable to their core application. They are also more interested in investing to complementary applications rather than trying to adapt their technology to a different application or market. The result implies that market and supply chain may have greater effect than technology relatedness on firms' technology development strategies.

The paper is organized as follows: Section II summarizes key literature on technology relatedness and adaptation. Section III presents information about survey subjects and key findings of the survey. Section IV discusses survey results. Section V concludes the study and identity areas for future work.

\section{TECHNOLOGY RELATEDNESS AND ADAPTATION}

Breschi et al. [1], state that "Firms follow a coherent pattern of technological diversification, which clusters around groups of technologies that share a common or complementary knowledge base, rely upon common scientific principles or have similar heuristics of search". Technology relatedness is observed when two technologies share common scientific principles with each other [2]. Adapting related technologies to new applications can be decisive for innovation, as many research suggest that innovation is a result of recombination and synthesis of existing and new knowledge [3-6]. Rigby [7] reports that firms would exploit 
the opportunity of adapting a technology for related application when there is a chance to do so. As an example, electronics firms of Taiwan were active players in the development of semiconductor technologies thanks to the relatedness of technology between these two industries. Colatat et al. [8] discuss the importance of semiconductor technologies in early development phase of solar photovoltaic. Majority of the studies focus on bibliometric studies especially backward citation and co-classification analyses [9]. In our terminology, technology refers to a mean of production which can be measured by, for example, patents. Application is utility gained by the consumption of a technology and can be represented by market sector. While technology adaptation exists, it is not clear how important technology adaptation is in firms' technology development strategies. This is an important subject to explore as technology diffusion across industries intensifies as can be observed from the growing blurriness of boundaries between industries.

\section{THE SURVEY}

The survey is conducted in World Future Energy Summit (WFES) 2012 and 2013. The participants of WFES, as one of the premium events of the renewable energy sector, are primarily firms in the business areas of renewable energy production and storage. The survey was distributed to the firms during the two conferences. The individuals who filled out the survey are those who are directly involved in the decision-making of technology development in the firms. For those firms who did not have qualifying respondents in the conferences, the contacts of the individuals who can be appropriate were collected. Then the survey was sent to these individuals with emails. We distributed 205 surveys, and yielded a total of 41 responses. The business domains of the surveyed firms are summarized in Fig. 1.

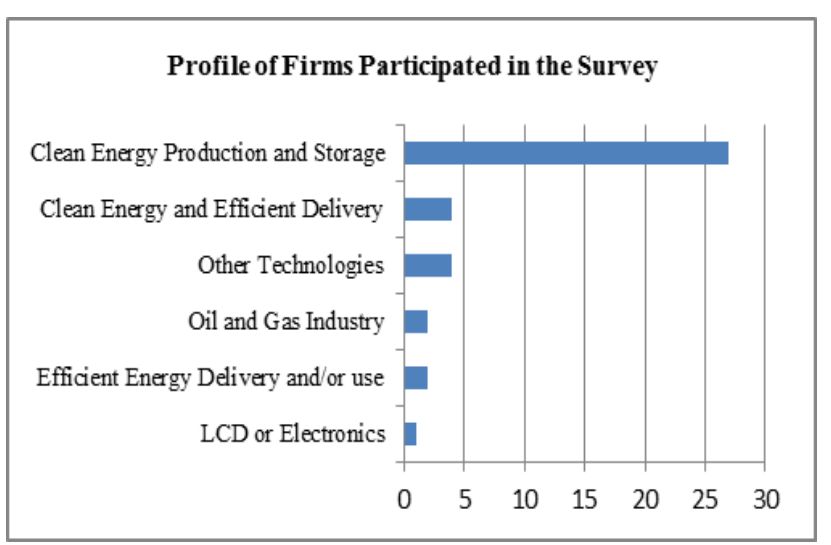

Fig. 1. Business domains of surveyed firms.

TABLE I: SCALE OF FIRMS PARTICIPATED IN THE SURVEY

\begin{tabular}{cr}
\hline Number of Employee (person) & \\
\hline Mean & 2547 \\
\hline Median & 30 \\
\hline Standard Deviation & 3896 \\
\hline 2011 Revenue (Million USD) & 995 \\
\hline Mean & 410 \\
\hline Median & 1465 \\
\hline Standard Deviation
\end{tabular}

Fig. 1 shows that the majority of the surveyed firms are from clean energy production and storage sectors such as the solar, wind, and geothermal industries. Some of the respondents are oil and gas and electronics firms. These firms are involved in renewable energy business even though traditionally they are not classified as renewable firms. Table I shows the statistics of total number of employee and annual revenue of firms (in million USD) participated in the survey ${ }^{1}$. As indicated in Table I, half of the surveyed firms have more than 30 employees and higher than USD 410 million revenue.

The survey, as shown in the appendix, is designed to identify (1) firms' awareness of core and related technologies regarding applications; (2) whether firms have defined the applicability of their technology to other applications; (3) the criteria of firms in defining applications that may become related to their technology; (4) whether firms are actively monitoring related applications; (5) if firms are actively pursuing technology adaptation (6) if and how would patents from public R\&D affect the firm's decisions for technology development of core and related applications. As patent is an important indicator of technology development [10], the survey investigates firms' criteria for acquiring external patents for core and related applications. Finally, the survey investigate firms' preference in adapting their technology to new applications and markets (technology oriented) versus developing related technology for their core applications (application oriented).

\section{RESUlTS AND DISCUSSION}

When technology relatedness exists, firms may only be active in its core applications rather than searching opportunities to adapt its technology for related applications. They may define core and related applications but not active in related applications. They can also be active in both core and related applications. Fig. 2 reflects the percentages of firms which have defined related applications to their technology and whether they are active on these domains.

\section{Firms' Focus on Core vs. Related Applications}

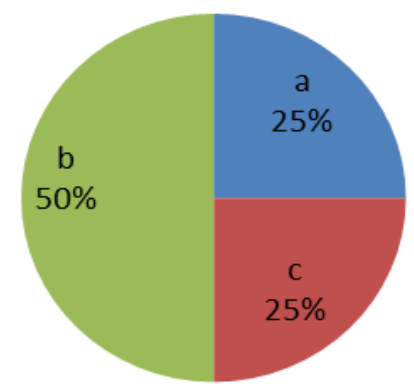

Fig. 2. Firms' focus on core vs. related applications.

Fig. 2 shows that half of the surveyed firms have defined both core and related applications and are active in both of them (a). Half of the firms have not been involved in related applications (b). $25 \%$ of the firms in general didn't even

\footnotetext{
${ }^{1}$ Three multinational oil and gas firms (Shell, Total, and Exxon) are excluded from the analysis due to their sheer size of revenue and employee compared to other firms.
} 
define the related applications yet (c).

It's critical to understand how firms identify core business applications. Fig. 3 shows number of times firms have chosen each option from a set of potential criteria with the reasoning as follows: Applications with high market growth potential (a) can be an important factor in deciding core applications. As market is the place for transaction, applications with high market share (b) are likely to be labeled as core applications. Sometimes market share may not be a sufficient in explaining the importance of an application. Contribution to existing revenue (c) may also be a key factor in defining core application. In similar approach, a firm may define its core applications based on expected major contributions to future revenue (d). Even though revenue and profit are highly related to each other, it is not necessary that high revenue yields also high profits. Hence, applications with major contribution to existing profit (e) may be more important than an application with high revenue but less profit. It is likely to hold for the applications expected to have major contributions to future profit (f). Other than market dynamics, some technologies in the form of key patent rights (g) are critical in defining whether an application is core or not. Applications that can contribute to the development of other businesses of interest (h) may also be at the core of interest.

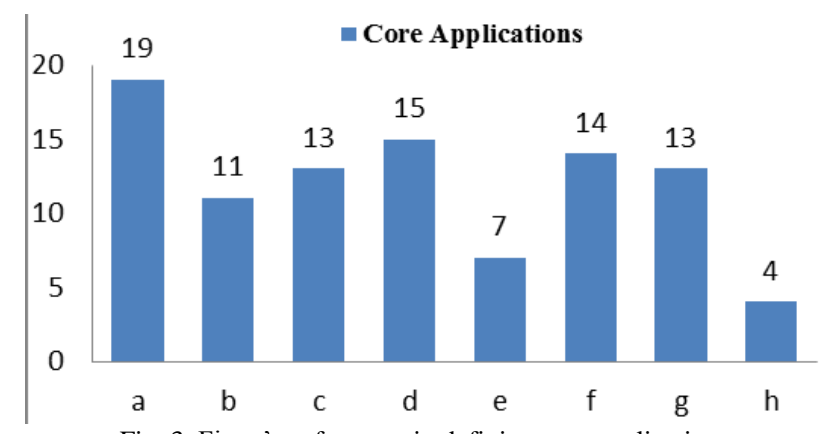

Fig. 3. Firms' preferences in defining core applications.

The result indicates that the majority of firms define core applications with the criteria of either high market share they already have (a), or expected to have (d), or a high profit (f). Key patent rights firms already have (g) are also important criteria along with along with applications contributing to the current revenue (c). Firms are not very concerned with current profit contribution in defining core applications (e). Meanwhile, the result also suggests that firms tend to forgo the spillover effect of core applications to the other applications (h).

Basically, Fig. 3 shows that firms regard current/future revenue and future profit along with key technology held as critical factors in defining the core applications. Short term profit or synergy with other business interests (applications) seem not so critical for firms in defining their core applications.

To check firms' perception of related applications, three options are given to choose. Firms on average don't regard substituting applications as related to their core applications. They give 3.3 in the scale of 1 to 5 for the option defining related applications as "Substitution to the core applications". This is in line with our definition which indicates that applications become related due to technology not because of competition. On the other side, firms consider adaptability of patents or technologies in defining related applications as important. They give 3.93, almost equal to 4 , for the option of "Applicability of patents or technologies already owned" in defining related applications. It's thus normal for firms to seek the adaptability of their technologies for new applications. Firms don't take expected short term profit into consideration when define related application. They give 3.4 for the option of "Relevant to firm's interest based on expected short term profit" in defining related applications. The results are reflected in Fig. 4 as follows:

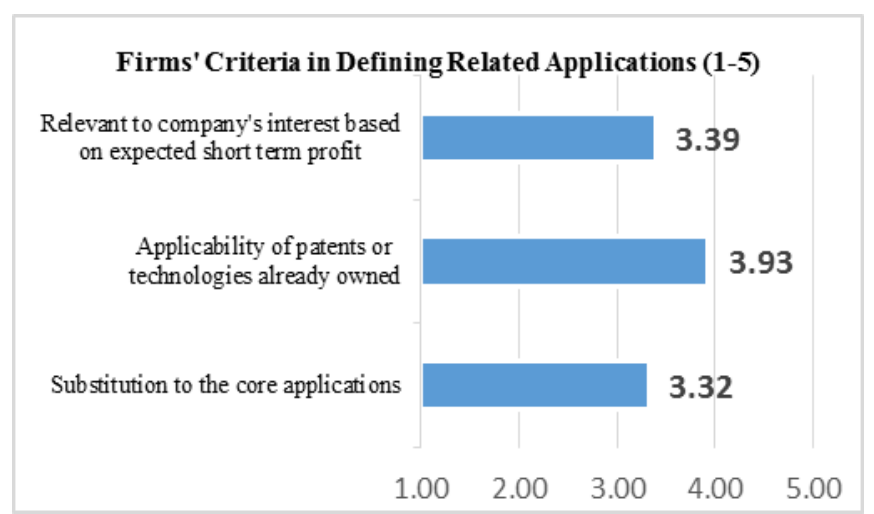

Fig. 4. Firms' decision criteria for related applications.

Fig. 4 suggests that firms may invest new but growing industries provided with adaptability of their current technology base. As majority of firms already defined and active in technology development for related applications, it can be concluded that firms are well aware of the opportunity of technology adaptation.

After identifying that firms are well aware of their technology's adaptability to related applications, it is critical to check how they consider this opportunity. As indicated earlier, patent is a well-known representative of technology and something that can be easily traceable. Patent activities are checked in tracing firms' technology strategy. It is asked whether firms file patents for their technology development in core applications. $60 \%$ of the participants said yes to that question which shows that patenting activity for the core applications is very common. Half of the firms are granted patents for technology of core applications. $45 \%$ of the participants bought patent from outside for the core applications. These findings suggest that firms are very active in developing or acquiring technology for the core applications. This is quite expected as energy industry is very competitive and dynamic.

For technology adaptation strategy, $37.5 \%$ of the firms are interested in adapting technology to the related applications. $30 \%$ of the respondents are granted patents for the related applications. Comparably low level of activity among the firms for related applications suggests that firms are either less interested in adapting technology for related application or the direct and opportunity cost associated with technology adaptation for related applications can be prohibitively high.

The survey shows that $32.5 \%$ of the firms are also interested to pay for patents that developed outside for the related applications. Firms regard monitoring technology development for related applications important. Even less 
than percentage of patents granted to core applications, firms are also active in searching for related applications.

Another aspect of technology development is firm interaction with outside or third party technology developers. For the core applications, firms are asked to choose between using technology developed in public domain and acquiring necessary technology from other firms. One third of the firms are only willing to get patents for core applications from public domain. A quarter of the firms are willing to pay patents from outside if it is needed. The remaining answers indicate no assessment.

It's expected that firms may not be very interested in acquiring external technology for a related application. Survey results show that $30 \%$ of the firms are looking to get patents public domain. However, another $30 \%$ of total are willing to purchase patents for their related applications if it is needed. Only $20 \%$ of the firms are willing to purchase patents related to both their core and related applications in general. It's better to check whether firms' strategies for technology acquisition change based on their size. The participated firms are separated into two types regarding size as large firms vs. small or medium-sized firms including the startups (USITC, 2010). US International Trade Commission (2010) defines small and medium enterprises (SMEs) as having at most 300 staff and 25 million US \$ of annual revenue. We will use this definition to separate the firms in our survey. It is found that almost half of the firms are SME whereas remaining half constitutes of large size firms.

Regarding the firm size effect on external technology acquisition, $60 \%$ of the firms which show interest in purchase patents for their core applications are large firms. 55 $\%$ of the firms willing to purchase patents for their related applications are also large firms. One may think that the size of the firm may affect the decision of patent acquisition from outside which in turn may affect firms' technology development strategy. Nevertheless, the close percentages suggest that firm size may not be so decisive in acquiring technology from outside if needed. This may indicate that firms are not concerned about R\&D costs in technology development.

We asked firms about their perception of working on both core and related applications simultaneously. Firms consider that technology developments for two different applications affect each other positively when they are complementary. This shows that firms are interested in developing and integrating applications complementary to their core applications.

Firms pursue preserving of core technology and core application rather than exploring new opportunities. This shows that firms are not very enthusiastic to search for related technology to their core applications. Applying the related technology to new applications or getting related technology for the core application may not be very attractive. The criteria of $R \& D$ decisions for firms are usually keep core technology competitive. Firms consider developing competitive technology for core and complementary applications very important. On the other side, extending the value of patents (adaptation) into new areas is not critical for firm's R\&D strategy. Firms are more concerned about their core market. Changing core technology (developed after so many years) with another seems not favored by firms.

\section{CONCLUSION}

This paper investigates firms' perspective on technology relatedness and adaptation with an intent to understand the dynamics of technology diffusion across industries. The result from a survey on renewable firms shows that the surveyed firms are more interested in strengthening their position in core business through vertical integration versus widening the applications with their existing technologies. While most of the firms $(75 \%)$ have identified related applications, many of them $(50 \%)$ prefer to develop complementary technologies for applications of core focus than to adapt their technology to different applications. The low level of willingness to buy patents for new applications and low level of R\&D investment (30\%) to adapt current technology to new applications support these findings. As a result, firms are reluctant to enter into new markets especially in emerging technologies even their technologies are adaptable. When adaptation is expensive, firms may be less willingness to expand to a related application as this strategy may incur a higher opportunity cost associated with maintaining their competitiveness in their core applications.

While patenting activity is considered a useful metric to track firm's technology development strategy and despite the above finding, most of the firms apply for patents for both core and related applications. In general, big firms are more flexible for the acquisition of patents from outside compared to SMEs due to resource availability. As a result, patents from public R\&D program as well as public financial support for private $R \& D$ can be very important for the technology development trajectories of small and medium enterprises.

This survey has been conducted primarily with energy firms. It is imperative to investigate technology adaptation pattern in other industries to distinguish the effects specific to the renewable energy industry. A direct interview with $R \& D$ departments of the firms will contribute to further understanding of this subject.

\section{APPENDIX: THE SURVEY}

1. Please indicate the core business of your firm:

a) Clean energy production and storage (e.g. renewable: solar, wind, bio fuel; energy storage, etc.)

b) Efficient energy delivery and/or use (e.g. smart grids, energy efficient buildings, clean mobility, low energy, etc.)

c) LCD (Liquid Crystal Display) or Electronic Components

d) Semiconductor technologies

e) Oil and Gas Extraction, Production and Retail Operations

$2-1$. Please indicate the number of employees in your firm.

2-2. Please indicate average annual sales of your firm (in million US dollars) in 2011.

3-1. Which of the following options best describes your firm's business activities?

a) My firm has identified business of core focus (i.e. core applications) and is engaging only in business of core focus

b) My firm has identified core applications as well as business with relevancy to core focus (relevant 
applications) and is actively engaging in both applications

c) My firm has identified both core applications and relevant applications and is actively engaging only in core application

3-2. How does your firm identify the core applications?

a) Applications with high market growth potential

b) Applications with high market share

c) Applications with major contributions to existing revenue

d) Applications expected to have major contributions to future revenue

e) Applications with major contributions to existing profit

f) Applications expected to have major contributions to future profit

g) Applications that firm holds key patent rights

h) Applications that can contribute to the development of other businesses of interest

i) Please specify other criteria if any

3-3. How does your firm identify related applications (rate with a scale of 1-5 with 1 being least important and 5 being most important)?

a) Substitution to the core applications

b) Applicability of patents or technologies already owned

c) Relevant to firm's interest based on expected short term profit

d) Please specify other criteria if any

3-4. Why if your firm does not engage in relevant applications?

a) Risk Concerns

b) Threat from development of relevant applications to the profit from core applications

c) Conflict of interests with suppliers and customers

d) Please specify other reasons if any

4-1. Has your Firm applied for patents for core applications in past 5 years?

4-2. Has your Firm acquired patents for core applications in past 5 years?

4-3. Has your Firm paid to use patents for core applications in past 5 years?

4-4. Has your firm developed technology for core applications in the past 5 years?

4-5. Does your firm monitor actively progress of technology development for core applications?

5-1. Has your firm defined the relevant applications?

5-2. Has your firm applied for patents for relevant applications in past 5 years?

5-3. Has your firm acquired patents for relevant applications in past 5 years?

5-4. Has your firm paid to use patents for relevant applications in past 5 years?

5-5. Has your firm developed technology for relevant applications in the past 5 years?

5-6. Does your firm actively monitor progress of technology development for relevant applications? (1-5)

$6-1$. Which one of the following options best describes your firm's criteria on knowledge requirement for technology development of core applications?

a) Only publicly available science is needed

b) Relevant patents can be purchased if needed c) No assessment has been made to provide the answer for this question

6-2. if your answer is b to question 6.1, what are the criteria of investment on technology development of core applications (feel free to click on multiple answers)?

a) Patent cost can be $>5 \%$ of overall project cost

b) Patent cost $<5 \%$ of overall project cost

c) Please specify if you have other criteria

6-3. Which one of the following options best describes your firm's criteria on knowledge requirement for technology development of relevant applications?

a) Only publicly available science is needed

b) Relevant patents can be purchased if needed

c) No assessment has been made to provide the answer for this question

6-4. if your answer is b to question 6.3, what are the criteria of investment on technology development of relevant applications?

a) Patent cost can be $>5 \%$ of overall project cost

b) Patent cost $<5 \%$ of overall project cost

c) Please specify if you have other criteria

7. In your view, when do technology developments for different applications affect each other positively?

a) Applications are complementary

b) Applications are substitutable

8. In your view, major innovation in your firm's core applications in the next 5 years will most likely come from:

a) Breakthrough in existing technology

b) Breakthrough in substitution technology

c) Breakthrough in complementary technology

d) Breakthrough in substitution application

e) Breakthrough in complementary application

f) Breakthrough in the business models for the core key apps

9. The criteria of $R \& D$ decisions for your firm tend to be more:

a) Application focused - Focus on developing competitive technology for core and relevant applications

b) Technology focused - Focus on extending the value of existing patents or technology

\section{ACKNOWLEDGMENT}

We thank the Masdar Institute for supporting financially this research initiative. We sincerely thank the participated firms and their respondents as for their patience and willingness to cooperate. We are also grateful to Zhanna Kapsalyamova, Sanaa El Waddi, Marwa Al Mohaideb, Meshayel Al Ali, Reem Al Junaibi, Wail Farouq Almaeeni, Mohammed Al Hadhrami and Marwan Al Nuaimi for assisting the execution of the survey.

\section{REFERENCES}

[1] S. Breschi, F. Lissoni, and F. Malerba, "Knowledge-relatedness in firm technological diversification," Research Policy, vol. 32, no. 1, pp. 69-87, 2003.

[2] B. Leten, R. Belderbos, and B. Van Looy, "Technological diversification, coherence, and performance of firms," Journal of Product Innovation Management, vol. 24, no. 6, pp. 567-579, 2007.

[3] K. J. Wong and R. Y. Chuang, "Cross-industry knowledge spillovers: A case study from Taiwan," in Proc. DRUID Conference, Copenhagen, Denmark, 2011 
[4] P. Colatat, G. Vidican, and R. K. Lester, "Innovation systems in the solar photovoltaic industry: the role of public research institutions," The Stavanger Innovation Summit: Transforming City Regions, June 15-16, 2009.

[5] G. Basalla, The Evolution of Technology, Cambridge University Press, Cambridge, 1988.

[6] R. Henderson and K. Clark, "Architectural innovation: the reconfiguration of existing product technologies and failure of established firms," Administration Science, quarterly 35, pp. 9-30, 1990.

[7] M. Weitzman, "Hybridizing growth theory," Proceedings of the American Economics Association, pp. 207-212, May 1996.

[8] A. Hargadon and R. Sutton, "Technology brokering and innovation in a product development firm," Administrative Science, quarterly 42, pp. 716-749, 1997.

[9] D. Rigby, The Geography of Knowledge Relatedness and Technological Diversification in US Cities (No. 1218), Utrecht University, Section of Economic Geography, 2012.

[10] I. Tsai, A. Kaya, T. Mezher, and N. Al Hosany, Technology Relatedness and Adaptation: Solar Photovoltaic Technology Development in the Semiconductor and Electronics Industries, 2013.

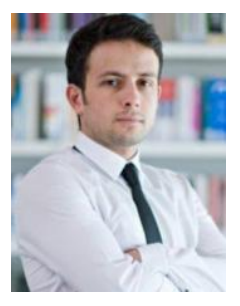

Abdullah Kaya is currently studying his $\mathrm{PhD}$ degree in the Department of Engineering Systems and Management at Masdar Institute of Science and Technology (MIST) in Abu Dhabi, UAE. He also got his MSc degree from the same department with a thesis titled as "Dynamics of Technology Strategy under Changing Regulatory Regimes: An Analytical Framework and a Case Study on the Global Solar Photovoltaic Industry". He holds BSc degree of industrial engineering from Middle East Technical University in Ankara, Turkey.

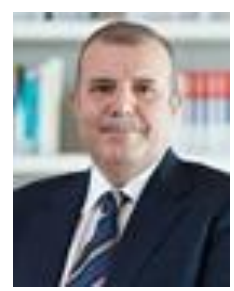

Toufic Mezher is with MIST at the Engineering Systems and Management Department. Before joining MIST, he was a professor of engineering management at the American University of Beirut from 1992 to 2007. He earned a BS degree in civil engineering from University of Florida, and a Master and ScD degrees in engineering management from George Washington University in 1988 and 1992 respectively.

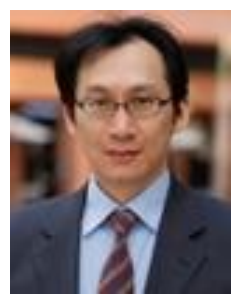

I-Tsung Tsai is a professor at MIST at the Engineering Systems and Management Department He holds a PhD degree from MIT while served as a water strategy consultant for the Singapore government. He was a visiting scholar of the Institute of Financial Research and Management, India in 2006. He focuses on carbon finance, infrastructure policy and information economics with a special focus of sustainability. He did his $\mathrm{PhD}$ dissertation on the implicit incentive mechanism embedded in financial contracts, and the effect of asymmetric information in the online auction markets. 